\title{
GPPS-BJ-2019-0084
}

\section{SINGLE DROPLET IGNITION MODELS BASED ON ENERGY BALANCE ANALYSIS AND VALIDATION}

\author{
Fang W \\ Beihang University \\ fwang@buaa.edu.cn \\ Beijing, China
}

\author{
Yang Zhao W \\ Beihang University \\ 2081416885@qq.com \\ Beijing, China
}

\author{
Min L \\ Beihang University \\ liminyaobao@163.com \\ Beijing, China
}

\author{
Cun F \\ Beihang University \\ 18810720977@163.com \\ Beijing, China
}

\author{
Jie $J$ \\ Beihang University \\ Jinjie@buaa.edu.cn \\ Beijing, China
}

\begin{abstract}
There is individual droplet burning phenomenon in spray flames but the ignition prediction and criteria are lack of both experimental and theoretical study. In the paper, firstly based on the energy balance analysis method, two new droplet ignition models were proposed by analyzing the single droplet evaporation and ignition process in relatively static high temperature air environment, which models can be used to predict the droplet ignition boundaries. Then, the single droplet of RP3 aviation kerosene, common kerosene and diesel was suspended in static air environment with ambient temperature from $855 \mathrm{~K}$ to $1085 \mathrm{~K}$ to test the ignition limits of the fuel droplet. The experimental ignition boundary was obtained by measuring and recording the minimum ignitable initial diameters of the experimental droplet in every temperature condition. The experimental results show that the ignitable minimum initial diameter of the fuel droplet decreases along with the increase of ambient temperature. And at the same ambient temperature, the minimum ignitable initial diameter of common kerosene droplet is the biggest, then is diesel and RP3 aviation kerosene is the smallest. Finally, the predicted ignition boundaries of the two new models were compared with the experimental data. And the comparison results show that the models' predictions are in good agreement with the experimental data, whose error is within $10 \%$.
\end{abstract}

\section{INTRODUCTION}

Spray combustion is widespread in the current combustion system, such as gas turbine engines, rocket engines, diesel engines and industrial furnaces( Kom and Sharma 2002 ). In these systems, the fuel is atomized into a large number of droplets to accelerate evaporation process and increase combustion efficiency by increasing the surface area. As the basic elements of fuel sprays, fundamental research on single droplet characteristics is a good stare of spray combustion characteristics.

The single droplet ignition phenomenon has been observed in the liquid fuel spray flames(Zhou 1961; Chiu and Liu1977; Chiu2000). Russo and Gomez(2006) studied the experimental instantaneous photos of ethanol/argon/oxygen flames. Both droplet evaporation with premixed flame amongst droplets mode and single droplet burning with individual diffusion flame mode existed in the spray flame. Agoston et al(1957)experimentally studied isolated acetone droplets ignition/burning characteristics in convection environment. The experimental results showed different combustion regimes of an isolated droplet, such as stationary envelope flame, envelope flame around a moving droplet, wake flame and boundary-layer flame.

Many researchers have investigated droplet ignition characteristics by both experimental research and numerical simulation study under different environmental parameters with different fuels. There are also studies on the droplet ignition under microgravity conditions and microexplosion phenomenon during ignition period(Chen et al2016). Rah (1986)mainly studied the ignition process of n-dodecane droplets. They found that the soot formation can be suppressed by delaying the ignition and the formation of an envelope flame around the droplets. Sangiovanni and Kesten(1975)using furfuryl alcohol and butyl alcohol investigated the influence of ambient temperature, oxygen concentration, droplet relative velocity, droplet size, and fuel type on single droplet ignition. They found that ignition delay time increases when ambient temperature and fuel volatility decrease and the droplet initial diameter increase. Chiu and 
Huang(1996)did both numerical simulation and experimental study on octane droplet with a diameter of $100 \mu \mathrm{m}$ at $800^{\circ} \mathrm{C}$. They proposed that even if the droplet Reynolds number and environmental temperature are the same, the droplet combustion condition is more than one kind, which is the droplet combustion modes' variety law. Bork et al(2017) measured the species concentration field in the wake of nheptane droplets with 2D Raman imaging. The temperature results suggested that the droplet is cooled due to evaporation rather than heated up towards its critical temperature. $\mathrm{Xu}$ et al(2017)studied combustion behavior of iso-octane droplets in the drop tower over a large range of initial droplet diameters $\left(0.5 \mathrm{~mm}<\mathrm{D}_{0}<5 \mathrm{~mm}\right)$. The combustion histories of iso-octane droplets showed a clear dependence on $\mathrm{D}_{0}$ that the combustion rate decreases with $\mathrm{D}_{0}$ increasing. Rao et al(2012)developed a comprehensive numerical model to analyze the isolated sodium droplet combustion in a mixed convective environment.

Most of the existing studies have used pure alkanes as fuel. However, in the actual combustion systems, diesel, kerosene and other blended fuels are more common used. The characteristics of these blended fuels were also studied, whether from experimental research or numerical simulation study. Segawa et al(2000)studied the ignition process of single droplets of binary mixtures. It was found that the ignition delay time of the binary fuel droplets decreased with increasing the volume concentration of the higher-volatility fuel. Takei et al(1993)observed the effects of fuel mixture ratio, initial droplet diameter, and ambient air temperature on ignition delay time using the mixture of n-heptane and nhexadecane. They found that the ignition delay time has the maximum value at an initial droplet diameter and this diameter increases with a decrease of the heptane concentration or the ambient temperature. Han et al(2017) investigated the droplet combustion behavior of diesel-benzyl azides blend droplet $(0$, $10 \%, 30 \%, 50 \%, 100 \%$ benzyl azides by weight) under atmospheric pressure. The results showed that the addition of benzyl azides increased the burning rate and caused microexplosion before extinction because of the appearance of liquid-phase reaction. It also showed that the ignition delay time decreased and the combustion duration first increased and then decreased with the increase of benzyl azides mass fraction. Burkert and $\mathrm{Paa}(2016)$ did single droplet ignition experiments of GTL kerosene, Jet A-1, and Exxsol D80 (reduced aromatics) in the temperature ranging from 550 to $900 \mathrm{~K}$ in air at 3 bars. Experiments showed that GTL kerosene cool flame ignition started significantly earlier than that of Exxsol D80 and Jet A-1, whereas the start of hot ignition differs only slightly for these three fuels.

No matter what kind of fuel researchers studied, the available work mostly focused on the ignition delay time and flame shape. A detailed analysis and solution on the droplet ignition criterion is not much. $\operatorname{Law}(1975,1978)$ gave an asymptotic theoretical analysis for droplet ignition criterion. The famous characteristic ignition-extinction S-shaped curve was produced. Frank and Kamenetskii analyzed ignition criterion of evenly mixed gas mixture. Zhuang and Zhou(1983)studied the unsymmetrical dimethylhydrazine droplet ignition character by experiments. A steady state analysis theory and a steady state simplified droplet ignition model was put forward. Ge and Fu(1997)studied the ignition process of multicomponent droplet in hot oxygenated ambience and an ignition criterion for multicomponent droplet was proposed. Wang et al(2013)judged the droplet ignition status by comparing the droplet chemical reaction time scale and the droplet evaporation time scale. Xi et al(2017) proposed series of new flash boiling sub-models inside a droplet, considering both the energy and momentum balances inside a droplet. This model quantitatively provided the boiling explosion time at wide ranges of fuel temperature and ambient pressure and can be used in predicting the secondary breakup of the droplet. Zhou et al(2017)proposed a new liquid phase model based on the assumptions of the 3rd-order polynomial temperature distribution and Hill's vortex model inside the droplet, which considered both temperature gradient and internal circulation inside the droplet. This new model displays the best performance with regard to predicting droplet evaporation in the later vaporizing period.

As for diesel and kerosene, which are widely used in industry, there are fewer theoretical work and experimental data for their ignition characteristics and much fewer for their ignition criteria in high temperature air stationary environment. It is necessary to study the applicably quantitative droplet ignition criterion for the droplet ignition boundary models to lay the foundation for the spray combustion understanding and numerical simulation. Through the investigation of previous work, it is found that the ignition criterion under the condition of forced convection proposed by Zhou(1986)is more suitable for technical application. However, this criterion only can be applied to forced convection environment. Therefore, single droplet ignition model for relatively static environment will be derived based on energy analysis method, which makes new ignition models. Then, the experimental study of the droplet ignition characteristics of common kerosene, diesel and RP3 aviation kerosene in high temperature air stationary environment was conducted.

\section{DROPLET IGNITION MODELS}

The droplet ignition models to be proposed in the paper are based on energy analysis method. The main idea is comparing about the magnitude between the heat release energy from chemical reaction and the heat absorption energy by liquid fuel evaporation. If the heat release is greater than the heat absorption, the energy could be assembled then ignition occurs. So large droplets are easier to be ignited than small droplets at the same temperature. Hence, the chemical reaction time scale and evaporation time scale is adopted to represent the heat release of chemical reaction and the heat absorption by droplet evaporation respectively.

Based on the energy analysis method, the droplet ignition process was analyzed by evaporation vs chemical reaction concept. That means the ignitable droplet would experience evaporation process and ignition process in a high temperature environment at the same time. The evaporation time scales as well as chemical reaction time scale were used to represent the competitive process. Whether an ignition process can 
successfully occur depends on the relative relationship between the evaporation time scale and the chemical reaction time scale. When the time scale of chemical reaction is smaller than the evaporation time scale, ignition will happen, otherwise it won't happen.

Figure 1 shows the ignition process of a single droplet.

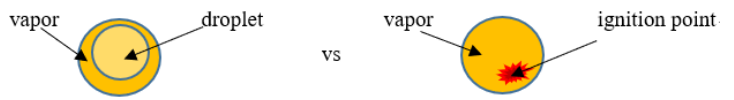

\section{Figure $1 \mathrm{~A}$ simple schematic diagram of droplet ignition process}

First, the droplet evaporates (left) making the fuel vapor distributed around the droplet surface and vapor spread to the air. Tanabe et al' research(1994)and the experiment in the paper suggest that some of the fuel vapor will goes down by the gravitational force. Then, when the local fuel vapor concentration reaches a certain value, a local ignition point appears (usually below the droplet) and the flame spreads rapidly, forming a completely enveloped flame until the droplet evaporates completely and burns out.

The basic droplet ignition model in this paper is using Frank-Kamenetsky approximation to deal with nonlinear reaction terms. As shown in Figure, a stagnant film is assumed around the droplet. The gas within the stagnant film is approximately divided into two region: a very thin reaction zone near the outer edge, named the first zone, where $r_{f}<r<$ $r_{1}$, and a pure heat transfer zone, named the second zone, where $r_{p}<r<r_{f}$ as shown in Figure. The thickness of the reaction zone is much smaller than that of the heat transfer zone. Figure 3 shows the distribution of temperature, concentration of each component in the inner region of the film during evaporation and combustion of the spherical liquid drop. Detailed explanation can refer to Zhou(1986).

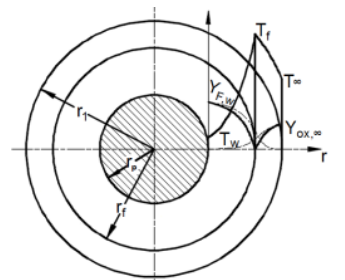

Figure 2. Droplet stagnant film

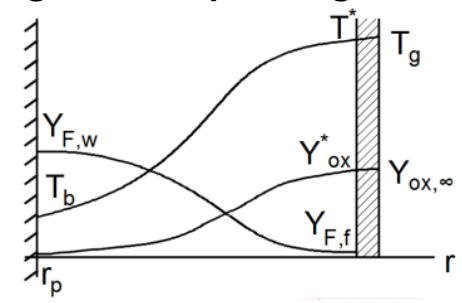

Figure 3. The variation curves of the parameters considering stagnant film

The reaction is most intense in the reaction zone. The temperature gradient is zero in this boundary. According to previous experiences in solving ignition problems, the change magnitude of parameters in the reaction zone can be expressed as

$$
R T_{\infty} / E
$$

The boundary temperature of reaction zone can be regarded approximately as

$$
T^{*} \approx T_{\infty}-\frac{R T_{\infty}^{2}}{E}
$$

Mean concentrations in reaction zone can be approximately taken as

$$
Y_{o x} \approx Y_{o x, \infty} \quad Y_{F} \approx Y_{F w} \frac{R T_{\infty}}{E}
$$

According to previous research results, neglect the change of the curvature and the convection term in the reaction zone, the energy equation can be expressed as

$$
\frac{d^{2} T}{d r^{2}} \approx-\frac{w_{s}}{\lambda_{\infty}} Q_{s}
$$

Integration of this energy equation from $r_{f}$ to $r_{1}$ is

$$
\left(\frac{d T}{d r}\right)_{f}=\sqrt{\frac{Q_{s}}{\lambda_{\infty}} \int_{T^{*}}^{T_{\infty}} w_{s} d T} .
$$

Where

$$
w_{s}=k_{o s} \rho_{\infty}^{2} Y_{F w} Y_{o x, \infty} \exp \left(-\frac{E}{R T_{\infty}}\right) .
$$

Integration of equation (2) is

$$
\int_{T^{*}}^{T_{\infty}} w_{s} d T \approx\left(1-\frac{1}{e}\right) \frac{R^{2} T_{\infty}^{2}}{E^{2}} k_{o s} \rho_{\infty}^{2} Y_{F w} Y_{o x, \infty} \exp \left(-\frac{E}{R T_{\infty}}\right) \text {.(3) }
$$

At the same time, the energy of the heat transfer zone ignores the reaction term and $\left(\frac{d T}{d r}\right)_{\mathrm{II}}$ is regarded approximately equal to the outer zone temperature gradient under the pure evaporation condition of droplets

$$
\left(\frac{d T}{d r}\right)_{\mathrm{II}}=\frac{G\left[c_{p}\left(T_{\infty}-T_{w}\right)+q_{e}\right]}{4 \pi r_{1}^{2} \lambda_{\infty}} .
$$

Where total mass flux is

$$
\begin{gathered}
G=2 \pi \frac{\bar{\lambda}}{c_{p}} N u_{T}^{*} r_{w} \ln \left[1+\frac{c_{p}\left(T_{\infty}-T_{w}\right)}{q_{e}}\right] . \\
r_{1}=r_{w} \frac{N u_{T}^{*}}{N u_{T}^{*}-2} . \\
N u_{T}^{*}=2+0.6 \operatorname{Re}^{0.5} \operatorname{Pr}^{0.33} .
\end{gathered}
$$

The coupling condition is that the heat release of reaction zone is equal to the heat transfer capacity to the surface of the droplet. Equalizing equation(1) to equation(4), the semitheoretical and semi-experimental ignition expressions of droplets under a convection condition can be expressed as:

$$
\frac{1}{d_{w}^{2}}\left[\frac{\left(N u_{T}^{*}-2\right)^{2}}{N u_{T}^{*}}\right]^{2}=A T_{\infty}^{n} \exp \left(-\frac{E}{R T_{\infty}}\right) .
$$

The calculation of total mass flux $G$ has two methods in this paper.

One method is use the total mass flux in static environment $G^{\prime}$ instead of $G$ 


$$
\begin{gathered}
G^{\prime}=4 \pi r_{w} \frac{\bar{\lambda}}{c_{p}} \ln \left[1+\frac{c_{p}\left(T_{\infty}-T_{w}\right)}{q_{e}}\right] . \\
r_{1}=r_{w} \frac{1}{1-\frac{2}{\alpha_{*} d_{w} / \lambda}} .
\end{gathered}
$$

A semi-theoretical and semi-experimental ignition expression of droplets under static environment was derived as:

$$
\frac{1}{r_{w}^{2}}\left[1-\frac{2}{\alpha_{*} d_{w} / \lambda}\right]^{4}=A T_{\infty}^{n} \exp \left(-\frac{E}{R T_{\infty}}\right) .
$$

The other method considered the nature convection caused by the temperature gradient in droplet surface. The temperature gradient causes a buoyancy:

$$
F_{b}=\rho_{\infty} g \Delta V .
$$

Introduce Rayleigh number representing the effect of buoyancy:

$$
R a_{T}=g \beta \Delta T \frac{\left(2 r_{w}\right)^{3}}{\lambda / c_{p} \rho} .
$$

The Nusselt number under the condition of natural convection can be expressed as:

$$
N u_{T}^{* \prime}=2+0.6 \operatorname{Ra}_{T}^{0.5} \operatorname{Pr}^{0.33} .
$$

Then another semi-theoretical and semi-experimental ignition expressions of droplets under natural convection was derived by using $N u_{T}^{* \prime}$ to replace $N u_{T}^{*}$ in equation (8)as

$$
\frac{1}{d_{w}^{2}}\left[\frac{\left(N u_{T}^{* \prime}-2\right)^{2}}{N u_{T}^{* \prime}}\right]^{2}=A T_{\infty}^{n} \exp \left(-\frac{E}{R T_{\infty}}\right) .
$$

In this form, the coefficients A is too large. We tried to aid a constant coefficient to environmental temperature to solve this problem. The equation (15) then become

$$
\frac{1}{d_{w}^{2}}\left[\frac{\left(N u_{T}^{* \prime}-2\right)^{2}}{N u_{T}^{* \prime}}\right]^{2}=A T_{\infty}^{n} \exp \left(-\frac{E}{R\left(1000 T_{\infty}\right)}\right) .
$$

Formula (15) and (16) are actually equivalent. And empirical coefficients $A$ and $n$ in the formula were determined by experimental data.

Then two models above and the criterion derived by Zhou covered all environmental condition. The whole criteria are show as equation (17).

$$
\left\{\begin{array}{ll}
\text { forced convection }(\mathrm{Re}>0): & \frac{1}{d_{w}^{2}}\left[\frac{\left(N u_{T}^{*}-2\right)^{2}}{N u_{T}^{*}}\right]^{2}=A T_{\infty}^{n} \exp \left(-\frac{E}{R T_{\infty}}\right) \\
\text { relatively static environment } \\
(\mathrm{Re}=0)
\end{array}: \begin{cases}\text { model } 1: & \frac{1}{r_{w}^{2}}\left[1-\frac{2}{\alpha_{*} d_{w} / \lambda}\right]^{4}=A T_{\infty}^{n} \exp \left(-\frac{E}{R T_{\infty}}\right) \\
\text { model } 2: & \frac{1}{d_{w}^{2}}\left[\frac{\left(N u_{T}^{* \prime}-2\right)^{2}}{N u_{T}^{* \prime}}\right]^{2}=A T_{\infty}^{n} \exp \left(-\frac{E}{R\left(1000 T_{\infty}\right)}\right)\end{cases}\right.
$$

In actual spray flame, both forced convection and relatively static conditions exist, so equation (17) considers all the situations and is more applicable compared with the equation (8). Most of the existing ignition models are directly related to fuel vapor concentration and oxygen concentration, which are difficulty to measure in experiments. And the criteria in the new models use parameters which are easy to measure such as temperature and is especially practical in solving engineering problems.

\section{EXPERIMENT}

The set of experimental equipment is quoted from (Wang et (2017).

The experimental conditions of three kinds of fuel are listed in Appendix A. They show the experimental temperature and the initial diameter of droplets. The initial diameter is obtained by comparison with the reference substance, and the size of the reference substance is measured by micrometer whose precision is $0.001 \mathrm{~mm}$. The detailed calculation method will be introduced later. The initial temperature of droplets is the indoor temperature, about $298 \mathrm{~K}$. The experimental pressure is atmospheric pressure, about 101 $\mathrm{kPa}$. The thermocouple used for temperature measurement has been calibrated and its accuracy is $1 \mathrm{~K}$.

When doing experiments, if the droplet is on fire, the obvious luminous flame can be observed from the photos, as shown in 4 . Then record the environmental temperature and store the photos. When the droplet was heated in the muffle furnace from room temperature, it experienced a very short time in which it's temperature field was highly heterogeneous to almost homogeneous and reached the highest temperature (with exponential growth), and which was far less than the ignition delay time in our experiment (Kuznetsov et al2018). So it is believed considered that the droplet temperature is uniform when it burns and can be regarded as a function of the ambient temperature. Therefore, in our experiment only the ambient temperature was recorded as the experimental condition.

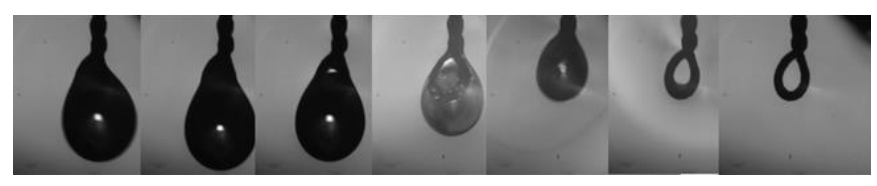

Figure 4 The ignition process of common kerosene

Wang et al (2018)is quoted in the experimental treatment method selected here. Under the dual effects of gravity and surface tension, the actual droplets are not spherical, but ellipsoidal. In this paper, the initial diameter is calculated by equivalent diameter. Where $d_{s}$ is the length of the short edge, $d_{l}$ is the length of the long edge. Equivalent diameter can be obtained by make them equal.

$$
d=\left(d_{s}^{2} d_{l}\right)^{\frac{1}{3}} \text {. }
$$

The photos were dealt by Photoshop software and Matlab program to obtain the initial diameter of droplets. As shown in Figure 5, The diameter of the hanging wire was selected as the measuring ruler.

In order to eliminate the errors introduced by the manual delineation, 6-8 initial photos in the same set of data of one experiment are dealt to get their diameters. Then an average value can be gotten. Since the interval time is $2 \mathrm{~ms}$ between every two photos, the droplets in these 6-8 photos are 
considered to be basically the same size. In addition, a photo with only the outline of the hanging wire when the droplet completely burned up is selected to get the measuring ruler, as shown in the left of Figure.
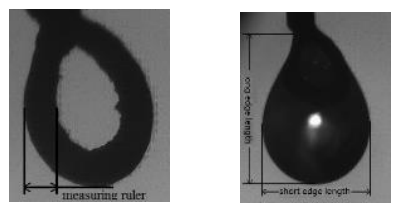

\section{Figure 5 Determination of measuring ruler (left) and the equivalent diameter of the droplet (right)}

The equivalent diameter of the droplet can be calculated through equation (18). Eliminate the largest and smallest values in 6-8 equivalent diameters, and the average of remaining 4-6 equivalent diameters which are relatively close to each other is taken as the initial diameter of the droplet.

\section{RESULTS AND DISCUSSION}

The final data obtained by the data processing method above are expressed in "ignition ambient temperature - initial diameter" scatter diagram, as shown in Figure 6.

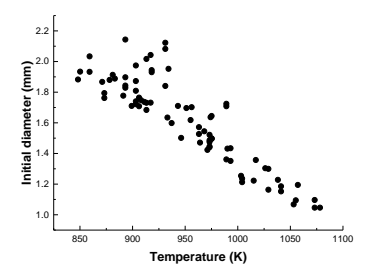

Figure 6 Droplet initial diameter versus ignition environmental temperature for common kerosene (original figure)

For common kerosene, all the valid experimental data of droplet ignition temperature and the droplet initial diameter were put on a scatter diagram, as shown in Figure 6. We recorded faithfully all the ignition condition of droplets and found that the boundary, i.e. the minimum initial diameter at a certain temperature, did exist. Because it was not sure whether there is such a boundary before the experiments, initial diameters of droplets at some temperatures are scattered. Just as shown in Figure 6, the points with the bigger initial diameter which are away from the ignition boundary are caused by this reason. To show the boundary better and clearly, these points were deleted as shown in Figure 7.

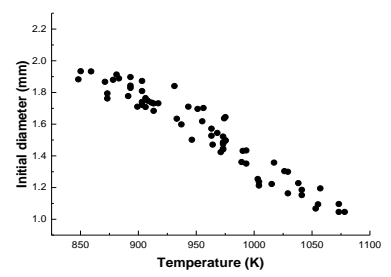

\section{Figure 7 Droplet initial diameter versus ignition environmental temperature for common kerosene (altered)}

When we look at the figures, we observe the changes in the relationship between temperature and diameter of the points on the boundary, or a trend of the whole data, rather than the changes of initial diameter of the droplet that can be ignited under a certain temperature. Deleting the points away from the boundary is just for better observation of the results so as to obtain the ignition boundary. The same way was used to deal with the original figures of RP3 aviation kerosene and diesel.

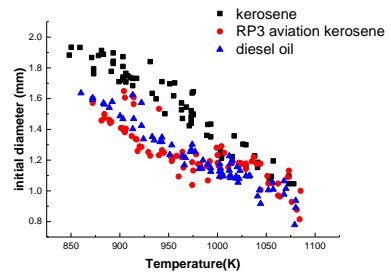

Figure 8 Droplet initial diameter versus ignition environmental temperature for three kinds of fuels

The figures of droplet initial diameter versus ignition environmental temperature of the three types of fuel after the removal of the points away from the boundary are put together, as shown in Figure 8. It shows that three kinds of fuel droplets present same features. Their minimum initial diameters decreased when the environmental temperature increased. For droplets on the ignition boundary, their ignition temperature and initial diameter change in an opposite direction. However, there is still a difference among three kinds of fuel. Among three kinds of fuel, common kerosene requires a higher temperature to be ignited which shows that it is not easy to combust. Then is diesel. And the RP3 is the most easily burning fuel.

It can be seen from the Figure 8 that the diameters of common kerosene, diesel and RP3 aviation kerosene droplets in experiment ranges from $0.8-1.9 \mathrm{~mm}$, which is much bigger than that in current combustion systems. Huang et al. (2007)studied the atomization characteristics of liquid rocket engine by using Laser Phase Doppler Particle Analyzer (PDPA). In his public literature, the mean droplet radius ranges from 30 to 60 microns. But in actual combustion chambers, the environmental temperature is higher than that in this paper. And droplets are in the forced convection flow. Both of them can accelerate evaporation process and increase combustion efficiency. Besides, the diameter of droplet studied experimentally by suspended droplet technique in literatures is about $0.5-1.5 \mathrm{~mm}$ (Segawa et al2000;Saitoh et al1982; Wong and Turns1987; Bergeron and Hallett1989). Although droplets in this paper is larger than those in actual combustion chambers, the idea of research content can be extended to practical application.

The ignition boundary is fit out based on these experimental data. The boundary is a range, so the fluctuation error of temperature and initial diameter within a certain range can be ignored. The size of droplet is very small compared with the inside size of the furnace. Therefore, the influence of the appearance of a droplet can be neglected for the furnace internal environment. Hence, the problem of heating rate is not important in this paper. The temperature measured by the thermocouple was used to replace the environmental temperature. Because the thermocouple and the droplet are very close and the droplet's influence on the environmental temperature is very small. Therefore, the error from here can be ignored, too. 
Kliachko(1960)did same experiments of n-octane droplets in the muffle furnace. He researched the ignition condition in stationary air of a high temperature from $733 \mathrm{~K}$ to $933 \mathrm{~K}$. His results also showed the minimum initial diameter can be ignited increased when environmental temperature decreased, as shown in Appendix B. Wong and Turns(1987)also did the ignition experiment with aluminum slurry droplets. They get the similar curve. These results consist with this paper.

This phenomenon is due to the combustion process which droplets experienced. It is the fuel vapor rather than the liquid droplet actually ignites. So liquid droplets must evaporate to fuel vapor and then combust. The droplet evaporates more slowly when the temperature is lower. The small droplet evaporates slowly in low temperature, so the fuel vapor concentration is too low to be ignited. Only a slightly larger droplet can provide an enough fuel vapor concentration to be ignited. With the increase of environmental temperature, evaporation speed of droplet is accelerated. A droplet with the same initial diameter evaporates more fuel vapor for ignition. Hence, the minimum initial diameter can be ignited increased when environmental temperature decreased.

The predicted ignition boundaries of two new ignition models were compared with the experimental results, as shown in Figure 9-11. And empirical coefficients $A$ and $n$ are fit by experimental data.

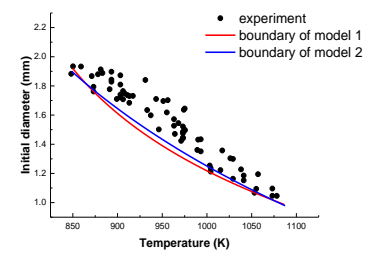

Figure 9 Comparison between two models' predictions and experimental results of common kerosene(Model 1:A=4.8508 $\times 10^{19} ; n=$ -0.01455 ; Model 2:A=3. $72 \times 10^{17}, \mathrm{n}=-5.23$ )

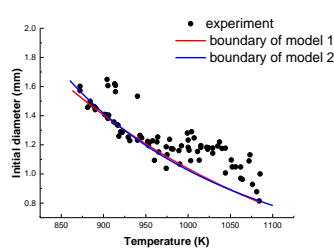

Figure 10 Comparison between two models' predictions and experimental results of RP3 aviation kerosene(Model 1:A=7.0834 $\times 10^{11} ; \mathbf{n}=$ 2. 73463; Model 2:A=1. $014 \times 10^{22}, n=-6.75$ )

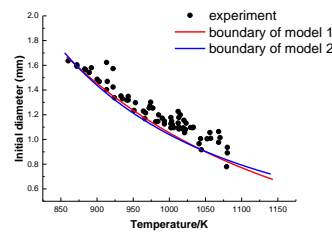

Figure 11 Comparison between two models' predictions and experimental results of diesel

(Model 1:A=3.1582 $\times 10^{11} ; n=2.83959$; Model

$2: A=2.246 \times 10^{26}, n=-8.33$ )
From figures above, we can find two droplet ignition models coincide well with experimental results of this paper. What need to be explained is that the concentration of experimental points in Figure 9-11 are not the trend, it's just because there has many measurement data points. The analysis of the uncertainty of the ignition criteria will be discussed next. For each fuel, the minimum ignition initial diameter at 5-6 temperatures are calculated and compared with the experimental values, as shown in table 1 .

Table 1 Relative error of two models

\begin{tabular}{|c|c|c|c|c|c|c|}
\hline \multirow[b]{2}{*}{ Fuel } & \multirow{2}{*}{$\begin{array}{c}\text { Tempe } \\
\text { rature( } \\
\mathrm{K})\end{array}$} & \multicolumn{3}{|c|}{ Initial diameter(mm) } & \multicolumn{2}{|c|}{$\begin{array}{l}\text { Relative } \\
\text { error }(\%)\end{array}$} \\
\hline & & $\begin{array}{c}\text { Experi } \\
\text { ment }\end{array}$ & $\begin{array}{c}\text { Mo } \\
\text { del } \\
1 \\
\end{array}$ & $\begin{array}{c}\text { Mo } \\
\text { del } \\
2 \\
\end{array}$ & $\begin{array}{c}\text { Mo } \\
\text { del } \\
1 \\
\end{array}$ & $\begin{array}{c}\text { Mo } \\
\text { del } \\
2 \\
\end{array}$ \\
\hline \multirow{3}{*}{$\begin{array}{l}\text { common } \\
\text { kerosene }\end{array}$} & 848 & 1.88 & 1.92 & 1.88 & 2.1 & 0 \\
\hline & 946 & 1.50 & 1.41 & 1.43 & 6.0 & 4.7 \\
\hline & 1055 & 1.09 & 1.06 & 1.10 & 2.8 & 0.9 \\
\hline \multirow{3}{*}{$\begin{array}{c}\text { RP3 } \\
\text { aviation } \\
\text { kerosene }\end{array}$} & 901 & 1.41 & 1.41 & 1.36 & 0 & 3.5 \\
\hline & 1003 & 1.09 & 1.02 & 1.01 & 6.4 & 7.3 \\
\hline & 1084 & 0.82 & 0.82 & 0.82 & 0 & 0 \\
\hline \multirow{3}{*}{ diesel } & 860 & 1.64 & 1.67 & 1.68 & 1.8 & 2.4 \\
\hline & 951 & 1.24 & 1.21 & 1.18 & 2.4 & 4.8 \\
\hline & 1079 & 0.78 & 0.84 & 0.78 & 7.7 & 0 \\
\hline
\end{tabular}

As shown in table 1, most of the relative errors of two models are no more than $10 \%$. Therefore, the prediction results of the two models are basically reliable.

And the values of empirical coefficients $A$ and $n$ of three kinds of fuel are close to each other, but there are also certain differences among them. This difference may relate to the chemical composition of fuel which will be tested later. And the values of $A$ and $n$ which are determined by experiments need further test and research. Based on theoretical analysis, the semi-empirical and semi-theoretical model extracts key factors and relations, and determines relevant parameters of the model in combination with experimental results. From the comparison results, this method is proved again to be effective and applicable in solving practical problems in engineering.

\section{CONCLUSIONS}

1. Aimed at the droplet burning phenomenon in spray flames, this paper proposed new ignition models which can be used under both relatively static and convective environment based on the energy analysis method. The main idea is comparing about the magnitude of heat release from chemical reaction and the heat absorption from liquid fuel evaporation. The evaporation process takes the energy away, while the chemical reaction heat release supplies energy for ignition. If the heat release is greater than the heat absorption, the ignition occurs. Instead, it doesn't happen. So the problem of droplet ignition can be seen as a competition between this two processes.

2. Single droplet of RP3 aviation kerosene, common kerosene and diesel was suspended in the relatively static environment with ambient temperature from $855 \mathrm{~K}$ to $1085 \mathrm{~K}$ to validate the two models proposed in the paper. The semitheoretical and semi-experimental ignition models can well 
describe the droplet ignition boundaries and the error between the predicted results and the experimental data is within $10 \%$.

3. The experimental study in this paper includes the effects of gravity and radiation and the errors in the experiment may be due to gravity and radiation. However, evaporation and chemical reactions are more important factors than gravity and radiation, other influencing factors need to be further studied.

4. The experimental results show that the minimum ignitable initial diameter of droplet decreases with the increase of ambient temperature within the experimental temperature. And at the same ambient temperature, the minimum ignitable initial diameter of kerosene droplet is the biggest among the three kinds of fuel, then is diesel and RP3 aviation kerosene is the smallest.

\section{NOMENCLATURE}

\begin{tabular}{|c|c|c|c|}
\hline$R$ & gas constant, & $\operatorname{Re}$ & Reynolds number \\
\hline$T$ & $\begin{array}{l}\mathrm{J} /(\mathrm{mol} \cdot \mathrm{K}) \\
\text { environmental } \\
\text { temperature, } \mathrm{K}\end{array}$ & $\operatorname{Pr}$ & Prandtl number \\
\hline$E$ & $\begin{array}{l}\text { activation energy, } \\
\mathrm{KJ} / \mathrm{mol}\end{array}$ & $d$ & diameter, mm \\
\hline$Y$ & mass fraction & $\Delta V$ & $\begin{array}{l}\text { volume difference, } \\
\mathrm{m}^{3}\end{array}$ \\
\hline$w_{s}$ & $\begin{array}{l}\text { reaction rate, } \\
\mathrm{kg} /\left(\mathrm{m}^{3} \cdot \mathrm{s}\right)\end{array}$ & $\Delta T$ & $\begin{array}{l}\text { temperature } \\
\text { difference, } \mathrm{K}\end{array}$ \\
\hline$\lambda$ & $\begin{array}{l}\text { heat conductivity } \\
\text { coefficient, } \mathrm{W} /(\mathrm{m} \cdot \mathrm{K})\end{array}$ & $R a_{T}$ & Rayleigh number \\
\hline$Q_{s}$ & $\begin{array}{l}\text { capacity of heat } \\
\text { transmission, W/m² }\end{array}$ & $\beta$ & stoichiometric ratio \\
\hline$k_{o s}$ & $\begin{array}{l}\text { pre-exponential } \\
\text { factor, } \mathrm{m}^{3} /(\mathrm{mol} \cdot \mathrm{s})\end{array}$ & $A$ & $\begin{array}{l}\text { empirical } \\
\text { coefficient }\end{array}$ \\
\hline$\rho$ & density, $\mathrm{kg} / \mathrm{m}^{3}$ & $n$ & $\begin{array}{l}\text { empirical } \\
\text { coefficient }\end{array}$ \\
\hline$G$ & mass flux, mol/s & & \\
\hline$c_{p}$ & $\begin{array}{l}\text { specific heat at } \\
\text { constant pressure, } \\
\mathrm{J} /(\mathrm{mol} \cdot \mathrm{K})\end{array}$ & Subscripts & \\
\hline$q_{e}$ & $\begin{array}{l}\text { latent heat of } \\
\text { evaporation, } \mathrm{J} / \mathrm{mol}\end{array}$ & $o x$ & oxygen \\
\hline$r$ & radius, $\mathrm{mm}$ & $\infty$ & environment \\
\hline$r_{1}$ & $\begin{array}{l}\text { radius of stagnant } \\
\text { film, mm }\end{array}$ & $\mathrm{F}$ & fuel \\
\hline$\alpha$ & $\begin{array}{l}\text { convective heat } \\
\text { transfer coefficient, } \\
\mathrm{W} /\left(\mathrm{m}^{2} \cdot \mathrm{K}\right)\end{array}$ & $\mathrm{w}$ & droplet surface \\
\hline$g$ & $\begin{array}{l}\text { gravitational } \\
\text { acceleration, } \mathrm{m} / \mathrm{s}^{2}\end{array}$ & $*$ & $\begin{array}{l}\text { the inner boundary } \\
\text { of the reaction zone }\end{array}$ \\
\hline$N u_{T}$ & Nusselt number & & \\
\hline
\end{tabular}

\section{ACKNOWLEDGMENTS}

This study was supported by National Key R\&D Program of China(2017YFB0202400,2017YFB0202402), the National Natural Science Foundation of China (91741125) and the Project of Newton International Fellowship Alumnus from Royal Society (AL120003).

\section{REFERENCES}

Kom S K and Sharma N Y. (2002).Energy and Exergy Balance in the Process of Spray Combustion in a Gas Turbine Combustor. Transactions of the Asme Serie C Journal of Heat Transfer, 124(5), 828-836.doi:10.1115/1.1484393.

Zhou L X.(1961).Research on Evaporation and Combustion of Single Oil Droplet and Liquid Spray (Isparenie I Gorenie Eginichniekh Kapel I paspeliaoniekx ridkikh Topliv, Russian). Lixing Zhou. Beijing: Higher Education Production. Chiu H H and Liu T. M. M. (1977).Group combustion of liquid droplets[J]. Combustion Science and Technology, 17(3-4), 127-142.

Chiu H H. (2000). Advances and challenges in droplet and spray combustion.I.Toward a unified theory of droplet aerothermochemistry. Progress in Energy and Combustion Science,26(4-6),381-416.doi:10.1016/s0360-1285(00)000162.

Russo S and Gomez A.(2006). Physical characterization of laminar spray flames in the pressure range $0.1-0.9 \mathrm{MPa}$. Combustion\&Flame,145(1-2),339-356. doi:10.1016/j.combustflame.2005.10.002.

Agoston G A, Wise H and Rosser W A.(1957). Dynamic factors affecting the combustion of liquid spheres. Symposiumon Combustion, 6(1),708-717.doi:10.1016/s00820784(57)80098-8.

Chen X, Khani E and Chen C P.(2016).A unified jet fuel surrogate for droplet evaporation and ignition. Fuel, 182,284291.doi:10.1016/j.fuel.2016.05.114.

Rah S C.(1986). Ignition and combustion of liquid fuel droplets: impact on pollutant formation. Combustion Science \& Technology, 48(5-6),273-284.

Sangiovanni J J and Kesten A S.(1975) A Theoretical and Experimental Investigation of the Ignition of Fuel Droplets.

Combustion Science \& Technology,16(1-2),5970.doi:10.1080/00102207708946793.

Chiu H H and Huang J S. (1996).Multiple-state phenomena and hysteresis of a combusting isolated droplet. Atomization and Sprays, 6(1),1-26.

Bork B, Preusche A, Weckenmann F,Lamanna,G and Dreizler A.(2017). Measurement of species concentration and estimation of temperature in the wake of evaporating nheptane droplets at trans-critical conditions[J]. Proceedings of the Combustion Institute, 36(2),24332440.doi:10.1016/j.proci.2016.07037.

Xu Y H, Michael C and Hicks C. (2017). Thomas Avedisian. The combustion of iso-octane droplets with initial diameters from 0.5 to $5 \mathrm{~mm}$ : Effects on burning rate and flame extinction. Proceedings of the Combustion Institute, 36(2),2541-2548.

Rao P M, Raghavan V, Velusamy K, Sundararajan T and Shet U S P. (2012).Modeling of quasi-steady sodium droplet combustion in convective environment. International Journal of Heat and Mass Transfer,55(4),734743.doi:10.1016/j.ijheatmasstransfer.2011.10.036.

Segawa D, Kadota T, Kohama R and Enomoto H.(2000). Ignition of binary mixture droplets by a propagating laminar flame. Proceedings of the Combustion Institute, 28(1),961968. doi:10.1016/s0082-0784(00)80302-1.

Takei M, Tsukamoto T and Niioka T. (1993). Ignition of blended-fuel droplet in high-temperature atmosphere. 
Combustion \& Flame,93(1-2),149-156. doi:10.1016/00102180(93)90089-1.

Han K, Chen H, Yang B, Ma X and Song Get.(2017). Experimental investigation on droplet burning characteristics of diesel-benzyl azides blend. Fuel, 190,32-40. doi:10.1016/j.fuel.2016.10.102.

Burkert A and Paa W. (2016).Ignition delay times of single kerosene droplets based on formaldehyde LIF detection. Fuel, 167,271-279. doi:10.1016/j.fuel.2015.11.051.

Law C K. (1975)Asymptotic theory for ignition and extinction in droplet burning. Combustion \& Flame, 24(1),89-98. doi:10.1016/0010-2180(75)90131-5.

Law C K.(1978). Theory of thermal ignition in fuel droplet burning. Combustion \& Flame, 31(3),285-296. doi:10.1016/0010-2180(78)90141-4.

Zhuang F C and Zhou J.(1983).A steady state theory of UDMH droplet ignition calculation. Journal of Engineering Thermophysics, 4(1),85-91.

Ge Y and Fu W B.(1997). Research on the ignition laws of the multicomponent mixed fuel droplets. Journal of Engineering Thermophysics, 18(5),653-656.

Wang F, Hu B and Huang Y.(2013).A two-phase turbulent combustion model and its validation for spray flames. Fuel, 113(2),280-286. doi:10.1016/j.fuel.2013.05.072.

Xi X, Liu H, Jia M,Xie M and Yin H.(2017). A new flash boiling model for single droplet. International Journal of Heat andMassTransfer,107,1129-1137.doi:10.1016/j.ijheatmasstransfer. 2016.11.027.

Zhou Z F, Li W Y, Chen B and Wang G X.(2017). A 3rd-order polynomial temperature profile model for the heating and evaporation of moving droplets .Applied Thermal Engineering,110(110),162-170. doi:10.1016/j.applthermaleng .2016.08.160.

Zhou L X.(1986). Combustion Theory and Chemical Fluid Mechanics. Beijing: Science Publication.

Tanabe M, Kono M, Sato J,et al.(1994). Effects of natural convection on two stage ignition of an n-dodecane droplet. Twenty-Fifth Symposium (International) on Combustion/The Combustion Institute, 455-461.doi:10.1016/s00820784(06)80674-0.

Wang F, Liu R, Zhang X Z, et al.(2017). Evaporation Law of Kerosene Single Droplet in Relative Stationary and Convection Environment[J]. Journal of Combustion Science and Technology, 23(6),485-491.

Wang F, Li M, Liu R, et al. (2018).A Single Droplet Burning Model for High Temperature Air Stationary Environment. Journal of Engineering Thermophysics, 39(7),1576-1584.

Kuznetsov G V,Piskunov M V,volkov,R S,and Strizhak,P A. (2018). Unsteady temperature fields of evaporating water droplets exposed to conductive, convective and radiative heating.Applied Thermal Engineering, 131,340355.doi:10.1016/j.applthermaleng.

Huang Bing and Zhang Nan.(2007). Prediction of droplet size distributions of primary atomization in liquid rocket engine, Journal of rocket propulsion, 33(2),31-39.

Saitoh T, Ishiguro S and Niioka T. (1982). An experimental study of droplet ignition characteristics near the ignitable limit. Combustion \& Flame, 48(1),27-32.doi:10.1016/00102180(82)90113-4.
Wong S C and Turns S R. (1987).Ignition of Aluminum Slurry Droplets. Combustion Science \& Technology, 52(4-6),221242.doi:10.1018/00102208708952578.

Bergeron C A and Hallett W L H. (1989).Ignition characteristics of liquid hydrocarbon fuels as single droplets. Canadian Journal of Chemical Engineering, 67(1),142-149.doi:10.1002/cjce.5450670120.

Kliachko L A and Istratova Z V.(1960). On Theory of Lower Limits of Flame Propagation in Two-Phase Mixtures. Proceedings of Third (in Russian), Moscow, 2: 48-57.

\section{APPENDIX A}

Appendix table 1 Experimental condition of common kerosene

\begin{tabular}{|c|c|c|c|c|c|c|c|c|}
\hline & & initi & & & initi & & & initi \\
\hline $\mathrm{N}$ & $\begin{array}{l}\text { Temp } \\
\text { eratur }\end{array}$ & $\begin{array}{c}\text { al } \\
\text { dia } \\
\text { met }\end{array}$ & N & $\begin{array}{l}\text { Temp } \\
\text { eratur }\end{array}$ & $\begin{array}{c}\text { al } \\
\text { dia }\end{array}$ & $\mathrm{N}$ & $\begin{array}{l}\text { Temp } \\
\text { eratur }\end{array}$ & $\begin{array}{c}\text { al } \\
\text { dia }\end{array}$ \\
\hline • & $\begin{array}{c}\mathrm{e} \\
T / \mathrm{K}\end{array}$ & $\begin{array}{c}\text { er } \\
\mathrm{d}_{0} / \\
\mathrm{mm}\end{array}$ & . & $\begin{array}{c}\mathrm{e} \\
T / \mathrm{K}\end{array}$ & $\begin{array}{c}\mathrm{er} \\
\mathrm{d}_{0} / \\
\mathrm{mm}\end{array}$ & . & $\begin{array}{c}\mathrm{e} \\
T / \mathrm{K}\end{array}$ & $\begin{array}{c}\mathrm{er} \\
\mathrm{d}_{0} / \\
\mathrm{mm}\end{array}$ \\
\hline 1 & 848 & $\begin{array}{c}1.8 \\
8\end{array}$ & 2 & 946 & $\begin{array}{c}1.5 \\
0\end{array}$ & 3 & 1055 & $\begin{array}{c}1.0 \\
9\end{array}$ \\
\hline
\end{tabular}

\begin{tabular}{|c|c|c|c|c|c|c|c|c|}
\hline \multicolumn{9}{|c|}{$\begin{array}{c}\text { Appendix table } 2 \text { Experimental condition of RP3 } \\
\text { aviation kerosene }\end{array}$} \\
\hline & & initi & & & initi & & & initi \\
\hline $\begin{array}{l}\mathrm{N} \\
\mathrm{o}\end{array}$ & $\begin{array}{l}\text { Temp } \\
\text { eratur }\end{array}$ & $\begin{array}{c}\text { al } \\
\text { dia } \\
\text { met }\end{array}$ & $\begin{array}{l}\mathrm{N} \\
\mathrm{O}\end{array}$ & $\begin{array}{l}\text { Temp } \\
\text { eratur }\end{array}$ & $\begin{array}{c}\text { al } \\
\text { dia } \\
\text { met }\end{array}$ & $\begin{array}{l}\mathrm{N} \\
\mathrm{O}\end{array}$ & $\begin{array}{l}\text { Temp } \\
\text { eratur }\end{array}$ & $\begin{array}{c}\text { al } \\
\text { dia } \\
\text { met }\end{array}$ \\
\hline · & $T / \mathrm{K}$ & $\begin{array}{c}\text { er } \\
\mathrm{d}_{0} / \\
\mathrm{mm}\end{array}$ & · & e & $\begin{array}{c}\text { er } \\
\mathrm{d}_{0} / \\
\mathrm{mm}\end{array}$ & · & $\begin{array}{c}\mathrm{e} \\
T / \mathrm{K}\end{array}$ & $\begin{array}{c}\mathrm{er} \\
\mathrm{d}_{0} / \\
\mathrm{mm}\end{array}$ \\
\hline 1 & 901 & $\begin{array}{c}1.4 \\
1\end{array}$ & 2 & 1003 & $\begin{array}{c}1.7 \\
0\end{array}$ & 3 & 1084 & $\begin{array}{c}0.8 \\
2\end{array}$ \\
\hline
\end{tabular}

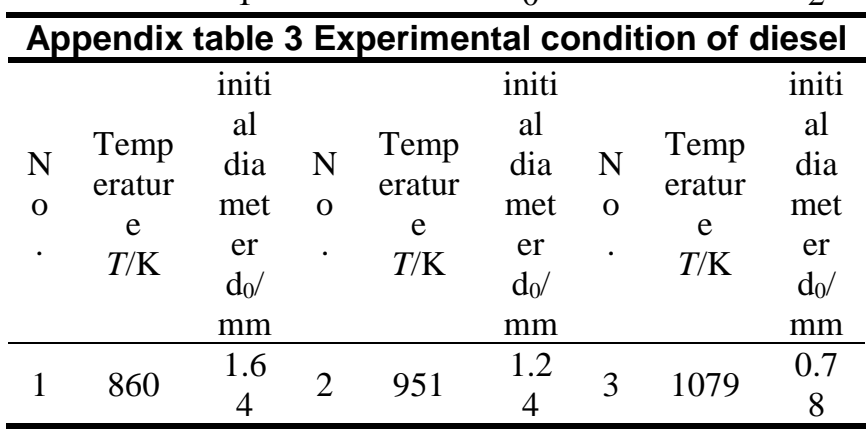

\section{APPENDIX B}

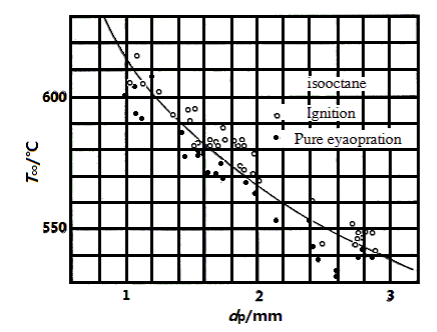

Appendix figure 1. Experimental results of Kliachko and theoretical curve of Lixing Zhou(Wong, Turns , 1987) 